\title{
Gestão agroecológica de microbacias hidrográficas através de técnicas de geoprocessamento e sensoriamento remoto - caso Fazenda Pantanoso ${ }^{1}$
}

\author{
Agroecological management of wathersheds trough remote sensing and geoprocessing \\ techniques - the Pantanoso Farm case
}

Fioravante Jaekel dos Santos ${ }^{2}$ Egon Klamt ${ }^{3}$

RESUMO

O manejo sustentado de agroecossistemas passa pelo planejamento de uso dos mesmos, para o que necessita serem avaliados os recursos naturais e as condições sociais, culturais e econômicas dos habitantes. Técnicas de geoprocessamento e sensoriamento remoto, que permitem avaliar os recursos de grandes áreas e anexá-los a bancos de dados georreferenciados, foram utilizados para caracterizar o meio físico e planejar o uso da fazenda El Pantanoso, Departamento de Cerro Largo, Uruguai. Dados topográficos, planialtimétricos, de solo e uso atual, foram usados para gerar os planos de informação: mapa base, modelo numérico do terreno, declividade, solos, aptidão de uso agrícola dos solos, uso atual, zoneamento ambiental e conflitos de uso. A pesquisa mostra que a região apresenta Planossolos, Argissolos, Chernossolos, Vertissolos, Organossolos, Neossolos e Gleissolos e que os mesmos apresentam ampla faixa de aptidão de uso, o que facilita seu zoneamento ambiental. Considerando-se que a tradicional pecuária desenvolvida nas áreas de topografia ondulada e arroz nas várzeas, constitui o uso adequado dos solos, então lavouras de arroz encontradas ao longo dos sistemas de drenagem, onde deveria ser mantida a vegetação ciliar natural, constitui o principal conflito de uso relacionado ao zoneamento ambiental da região. O geoprocessamento e sensoriamento remoto mostraram-se eficientes no planejamento de uso da Fazenda Pantanoso.

Palavras-chave: recursos ambientais, planejamento de uso, conflitos de uso.

\section{ABSTRACT}

The sustainable management of agro-ecological systems go through the planning of their use. To reach this objective, the natural resources as well as the social, cultural and economical conditions of the inhabitants of the study area need to be evaluated. Remote sensing and geoprocessing techniques, which permit the evaluation of the natural resources and organize georeferenced data bases, were applied to characterize the physical environment and to plan the use of the El Pantanoso Farm, Cerro Largo Department, Uruguay. Topographic, planialtimetric, soil and present land use data were used to generate the following information plans or levels: basic map, numerical model of the terrain, slope, soils, land capabilities map, present land use, environmental zoning and land use conflicts. The data obtained show that at the Pantanoso farm, Planosols (Albaqualfs, Natraqualfs), Argisols (Paleudults, Rodudalfs), Chernosols (Argiudolls), Vertisols (Paluderts), Gleysols (Haplaquolls), Organosols (Histosols) and Lithosols (Hapludolls), predominate and that these soils present ample variation of classes of land capabilities, which facilitates their agroecological zoning. If we consider that cattle-raising at the upland soil and cultivation of rice at lowlands, constitutes adequate land use, than the rice fields found along the drainage systems, where the natural gallery vegetation should have been maintained, constitute the main conflict related to the agroecological zoning of the farm. Remote sensing and geoprocessing techniques were efficient tools on the planning of the Pantanoso Farm.

Key words: environmental resources, planning the use, conflits of use.

\section{INTRODUÇÃO}

O manejo sustentado dos agroecossistemas passa pelo planejamento de uso dos mesmos, com uso de conceitos introduzidos para a abordagem da complexidade ambiental, com avaliação dos problemas levando em conta seus vários aspectos interdependentes: geologia, solos, vegetação, clima, uso atual, hidrologia e aspectos antrópicos (SANTOS, 1996).

O melhor uso do solo, segundo STALLINGS (1967), depende de suas características, localização, tamanho da propriedade, disponibilidade de recursos e habilidades do proprietário para usá-lo

1Parte da Dissertação de Mestrado do primeiro autor apresentada no Centro Estadual de Pesquisa em Sensoriamento Remoto e Meteorologia CEPSRM - Universidade Federal do Rio Grande do Sul (UFRGS) em 1999.

${ }^{2}$ Diretor da Área de Geomática, Grupo Especial de Estudo e Proteção do Ambiente Aquático (GEEPAA), Rua da Luz, 07, 96015-570, Pelotas, RS. ${ }^{3}$ Professor Titular Aposentado do Departamento de Solos, Faculdade de Agronomia, UFRGS, Consultor do Instituto Interamericano de Cooperação Para a Agricultura (IICA), em atividade na Divisão Agrária / Gabinete da Reforma Agrária, Porto Alegre, RS. Email:egonklamt@yahoo.com.br. Autor para correspondência. 
adequadamente. A adaptabilidade às atividades agrosilvopastoris diz respeito à sua capacidade de uso, que é conceituada como sendo a adequabilidade do uso dos solos para pastagens, lavouras, frutíferas, florestas, etc., de modo que a sua degradação seja menor possível (LEPSCH, 1983). Assim, cada hectare de terra deve ser cultivado segundo as suas reais aptidões, utilizando uma tecnologia que respeite e promova ao máximo o equilíbrio ecológico entre a fauna, flora, água, ar e o homem. Deste modo, o estabelecimento do melhor uso requer não só o estudo do solo em todas as suas características e detalhes, mas também o conhecimento de tecnologias próprias e adequadas a cada caso (RIO GRANDE DO SUL, 1994; STRECK et al., 2002).

As conseqüências da má utilização dos solos redundam, em um primeiro momento, na sua degradação física, química e biológica, que resultará na gradativa diminuição do seu potencial produtivo. Concomitantemente, com a desagregação do solo haverá a aceleração do processo de erosão com o posterior assoreamento de rios, barragens, bem como poluição dos recursos d'água por pesticidas e adubos químicos contidos na terra erodida.

Avaliar a sustentabilidade de sistemas de produção em propriedades rurais ou em nível de bacia hidrográfica, comunidades ou municípios, é uma tarefa necessária, mas complexa. Várias questões metodológicas e interações estão presentes neste tipo de caracterização e avaliação de uma agricultura sustentável, muitos deles relacionados com escala e tamanho das áreas em estudo ( FARSHAD \&ZINCK, 1993;ZINCK\&FARSHAD,1995). Muitos sistemas que apresentam alta sustentabilidade emnível de propriedade rural, quando são generalizados para uma região, podem redundar em fracassos devido a mudanças nas condições ambientais. A falta de metodologias que permitam a avaliação da sustentabilidade agrícola de sistemas de produção, integrando a análise dos fatores ambientais e os sistemas socioeconômicos mais amplos, com uma visão espacial e temporal dos problemas é um fato incontestável (MIRANDA et al.,1995).Os sistemas de informações geográficas são ferramentas cada vez mais utilizadas nos processos de pesquisa e planejamento econômico, territorial e ambiental.(BURROUGH, 1987; CROSTA, 1997;PIROLI et al., 2002).

O objetivo deste trabalho é caracterizar o meio físico, para subsidiar o planejamento do mesmo e a partir disto permitir o monitoramento a curto, médio e longo prazo, dos efeitos das atividades antrópicas oriundas do planejamento, visando tanto a preservação, como a otimização do uso dos recursos ambientais, num modelo acessível e de relativo baixo custo, aplicável a propriedades rurais, microbacias, áreas municipais ou regiões medianamente homogêneas, com características geográficas e socioeconômicas semelhantes, utilizando sistemas de geoprocessamento e sensoriamento remoto.

\section{MATERIAL E MÉTODOS}

Localização e características da área de estudo

A área de estudo que compreende a fazenda

Pantanoso, está localizada no Departamento de Cerro Largo, ao norte de Melo e sudoeste de Aceguá, entre as coordenadas Longitude $54^{\circ} 27^{\prime} 15^{\prime \prime} /$ Latitude $32^{\circ} 00^{\prime} 33^{\prime \prime}$ e Longitude $54^{\circ} 17^{\prime} 41^{\prime \prime}$ / Latitude 31 ${ }^{\circ} 53$ '37'. O limite sul da fazenda é o banhado de Aceguá, ao norte o Camino Astorga Arriera, ao leste o arroio Pantanoso, a oeste não existem acidentes geográficos significativos sendo seu limite propriedades particulares nesta direção. A fazenda apresenta 11.125ha de área.

Segundo o Sistema Universal de Classificação Climática de Köppen, o clima é Temperado Úmido, na variedade de Clima subtropical ou Virginiano, do tipo "cfa". A subcategoria "f" corresponde a chuvas distribuídas ao longo do ano e a variação tipo "a" relativa a verões muito quentes, quando a temperatura do mês mais quente supera os $22^{\circ} \mathrm{C}$, havendo registros de máxima absoluta de $42^{\circ} \mathrm{C}$, invernos bastante frios, podendo ocorrer geadas de abril a outubro.

O regime pluviométrico da região é tido como normal, apresentando média anual em torno $1260 \mathrm{~mm}$, como o observado nos dados registrados pela FEPAGRO e publicados no Atlas Agroclimático do Estado do Rio Grande do Sul (RIO GRANDE DO SUL, 1989). Devido a presença de solos rasos e com baixa capacidade de armazenamento de água, ampla predominância de pastagens, e cobertura florestal restrita às matas nativas ciliares e bosques de eucalipto, a incidência solar leva a um rápido aquecimento, com alta evapotranspiração causando balanço hídrico negativo nos meses de novembro a início de março (SANTOS, 1999).

Nesta região, segundo ALTAMIRANO et al. (1976) e DURÁN et al. (1979) ocorrem predominantemente Chernossolos, Planossolos, Vertissolos, Gleyssolos, Argissolos em relevo suave ondulado a ondulado e Neossolos Litólicos em relevo ondulado a forte ondulado, onde afloramentos de rochas são comuns.

Métodos usados

Para a utilização de Sistema de Informações Geográficas (SIG) os dados foram organizados em

Ciência Rural, v.34, n.6, nov-dez, 2004. 
planos de informações (PIs), a seguir relacionados, utilizando Idrisi 1, MiniCAD7 e outros softwares específicos para cada recurso analisado:

PI 1: mapa base

O mapa base foi extraído das cartas geográficas Zanja Honda e Aceguá, Serviço Geográfico Militar Uruguaio, que juntas contemplam a área de estudo, e por estas, todos os PIs foram ajustados e georreferenciados, para manter a base de dados com única referência espacial e escala de $1: 20.000$.

\section{PI 2: MNT}

Modelo numérico de terreno, foi produzido através da digitalização das cartas do Serviço Geográfico Militar Uruguaio, com curvas de nível de 10 em $10 \mathrm{~m}$ e curvas suplementares de $5 \mathrm{~m}$, obtidas por interpolação.

\section{PI 3: declividade}

Os mapas de declividade foram gerados a partir do MNT, dividindo-se, assim, a área por extratos de declividades médias $(0$ a $3,>3$ a $6,>6$ a $12,>12$ a 24 e $>24 \%$ ).

\section{PI 4: solos}

Mapa de solos obtidos pela checagem a campo do mapa da CO.N.E.A.T (Comisión Nacional de Estudio Agroeconómico de la Tierra). Diversos delineamentos por não conferirem com a realidade de campo foram traçados sobre fotos aéreas e posteriormente digitalizados. As descrições morfológicas dos solos e dados analíticos obtidos na Carta de Reconhecimento de Suelos del Uruguay Tomo I - Clasificacion de suelos (ALTAMIRANO et al., 1976) e Tomo III - Descripción de las Unidades de Suelos (DURÁN et al., 1979 e DURÁN et al.,1985), foram analisados e os solos classificados segundo o Sistema Brasileiro de Classificação (EMBRAPA, 1999) e as classes de solos assim obtidas foram usadas para confeccionar a legenda do mapa de solos. A classificação segundo o Soil Taxonomy (USA, 1994) efetuada pelos técnicos uruguaios, foi reavaliada e também apresentada.

\section{PI 5: aptidão de uso agrícola}

O mapa de aptidão de uso dos solos foi obtido pelo enquadramento das classes de solos do PI4 numa das classes de aptidão de uso descritas em RAMALHO FILHO \& BEEK (1995). Para tanto, as características morfológicas, físicas e químicas de cada classe de solo foram analisadas quanto à deficiência em fertilidade natural, de água, suscetibilidade a erosão e impedimento a mecanização. Cada um destes fatores foi analisado quanto as classes de limitação $\mathrm{N}=\mathrm{Nula}, \mathrm{L}=$ ligeira, $\mathrm{M}=$ moderada, $\mathrm{F}=$ forte $\mathrm{e} \mathrm{MF}=$ muito forte. Estas informações serviram de base para entrar no Quadro Guia para Solos das Regiões Subtropicais (RAMALHO FILHO \& BEEK, 1995) e os subgrupos de Aptidão Agrícola determinados nos sistemas de manejo: $\mathrm{A}=$ primitivo, $\mathrm{B}=$ intermediário e $\mathrm{C}=$ avançado.

PI 6: uso atual

O mapa de uso atual foi produzido através de classificação digital supervisionada das imagens de satélite LANDSAT-5, órbita 223, ponto 82 de 0201-96 nas bandas 3, 4, 5 e 7, com checagem de campo e informações complementares do administrador da fazenda.

\section{PI 7: zoneamento ambiental}

O mapa de zoneamento ambiental foi produzido pela análise de todos os planos de informações anteriores com a introdução da legislação ambiental vigente (Lei no $\mathbf{4} .771$, de 15 de setembro de 1965, que institui o Código Florestal e suas respectivas alterações até o ano de 1999), que define as áreas de: preservação permanente, de conservação, de uso intensivo e de diferentes restrições de uso de acordo com a aptidão agrícola.

PI 8: conflitos de uso

Pela sobreposição e cruzamento do PI6 uso atual, com o PI7 zoneamento ambiental, foi gerado o mapa de conflito de uso, classificando as áreas segundo: a) sub-utilizadas, áreas utilizadas com intensidade inferior ao indicado no zoneamento, b) adequado, áreas de uso condizente com a aptidão, c) sobre-utilizadas, áreas utilizadas mais intensamente que o indicado, e d) áreas de conflito ambiental.

\section{RESULTADOS E DISCUSSÃO}

Relação superfícies e solos

A digitalização das curvas de nível das cartas do serviço geográfico militar do Uruguai de 10 em $10 \mathrm{~m}$ e curvas suplementares de $5 \mathrm{~m}$, permitiram produzir o modelo numérico do terreno da Fazenda Pantanoso e, pela estratificação das declividades, confeccionou-se o mapa de declividade da mesma, apresentado na figura 1 . 


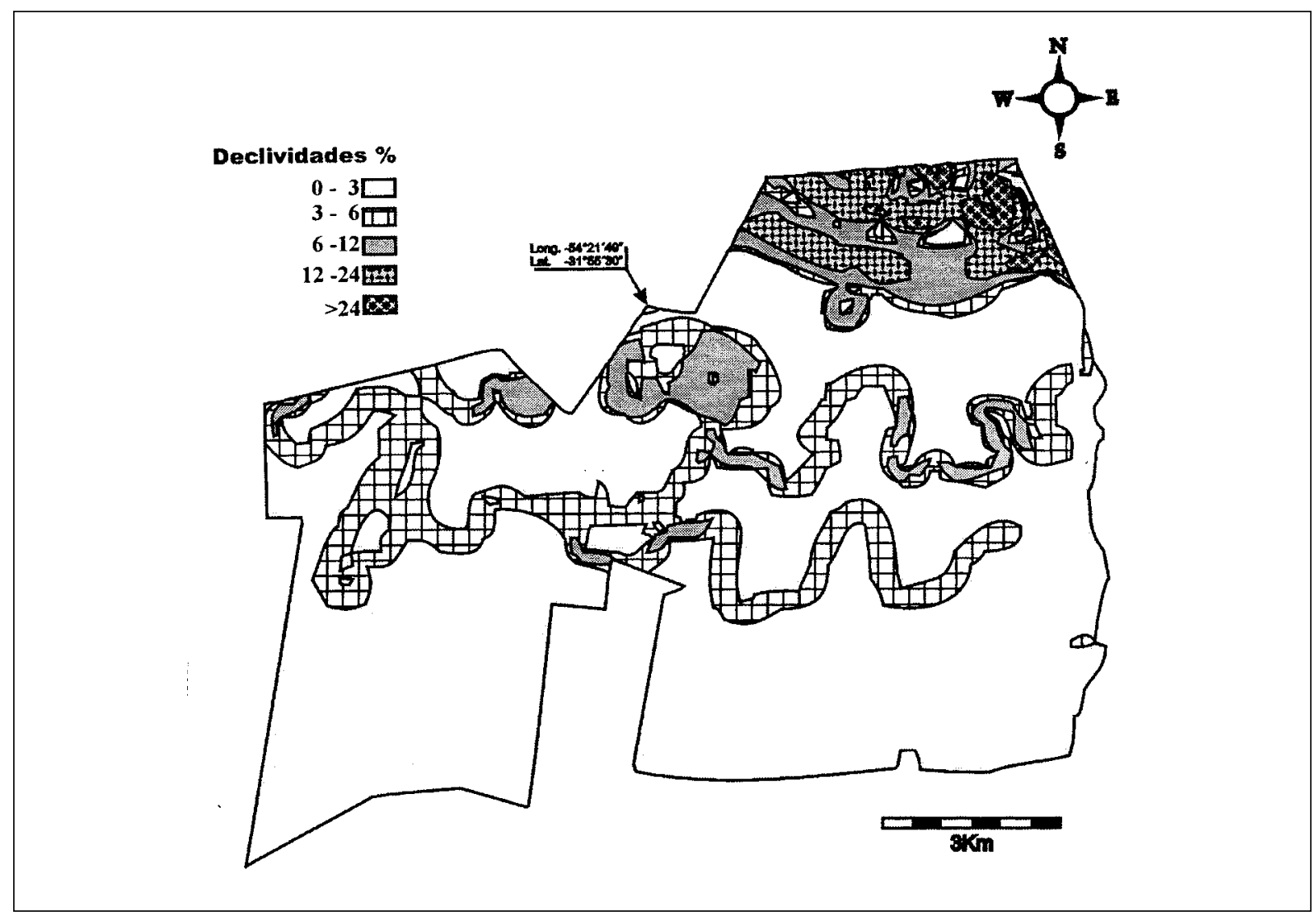

Figura 1 - Mapa de declividade da Fazenda Pantanoso

A topografia da área de estudo apresenta-se escarpada no norte da propriedade (Serra Aceguá), suave ondulada em sua porção central e plana ao sul (Banhado Aceguá). O PI3 declividade é uma informação que auxilia na elaboração do mapa de aptidão de uso agrícola das terras, e também utilizado para a interpretação e aplicação da lei que define as áreas de preservação permanente, que são as áreas com declividades maiores que $100 \%$ ou $45^{\circ}$ de declividade.

No mapa de solos obtido pela verificação a campo dos mapas de ALTAMIRANO et al. (1976) e DURÁN et al. (1979), corrigiu-se delineamentos e ajustou-se a ocorrência das classes de solos. As classes de solos assim obtidas foram usadas para confeccionar a legenda do mapa de solos mostrado na tabela 1 e o mapa de solos na figura 2. A classificação segundo o Soil Taxonomy (USA, 1994) efetuada pelos técnicos uruguaios foi reavaliada e também apresentada na tabela 1 .

O mapa de solos indica que Neossolos Litólicos predominam nas áreas forte onduladas situadas no extremo norte da fazenda; Argissolos Vermelhos-Amarelos associados a Argissolos Acinzentados e Planossolos Hidromórficos Nátricos nas áreas suave onduladas a onduladas da parte central e as demais classes de solo, ou seja, Planossolos, Chernossolos, Vertissolos, Gleissolos, Organossolos e Neossolos Flúvicos, nas áreas planas a suave onduladas da metade sul da fazenda.

Aptidão de uso agrícola dos solos e uso atual

O mapa de Aptidão de Uso Agrícola dos Solos mostrado na figura 3 , foi obtido pela análise e interpretação das características das classes de solos do PI4: solos; somado às características ambientais,como relevo, clima, uso atual, entre outras, seguido do enquadramento destes solos numa das classes de aptidão de uso descritas em RAMALHO FILHO et al. (1995). Segundo este mapa, os Chernossolos Argilúvicos Órtico Vértico (MTe), Chernossolos Ebanicos Órticos (MEk), Argissolos Acinzentados (PACe) e Vertissolo Hidromórfico Carbonáticos (VGk), enquadramse no subgrupo de aptidão regular 2abc (1104ha) nos sistemas de manejo primitivo (A), intermediário (B) e avançado (C), sendo os solos de melhor aptidão de uso agrícola da fazenda em 
Tabela 1 - Legenda do Mapa de Solos e da Aptidão de Uso Agrícola da Fazenda Pantanoso.

\begin{tabular}{|c|c|c|c|}
\hline \multirow{2}{*}{ Símbolo no mapa } & \multicolumn{2}{|r|}{ Classes de solos } & \multirow{2}{*}{$\begin{array}{l}\text { Classe de aptidão } \\
\text { de uso }\end{array}$} \\
\hline & Soil Taxonomy USA, 1994 & $\begin{array}{l}\text { Sistema Brasileiro de Classificação (EMBRAPA, } \\
1999)\end{array}$ & \\
\hline PVAa & Rhodic Paleudult & Argissolo Vermelho Amarelo Alumínico & $2(\mathrm{~b}) \mathrm{c}$ \\
\hline $\mathrm{SGe}$ & Mollic Albaqualf & Planossolo Hidromorfico Eutrófico & $2(a b) c$ \\
\hline SNk & Typic Natraqualf & Planossolo Nátrico Carbonático & $4 \mathrm{p}$ \\
\hline MTo & Vertic Argiudoll & Chernossolo Argilúvico Ortico Vértico & $2 a b c$ \\
\hline GMe & Typic Haplaquoll & Gleissolo Melânico Eutróficos & $3(\mathrm{bc})$ \\
\hline PVAd - PACe - RRd & $\begin{array}{c}\text { Typic Rodudalf - Typic Argiudoll - } \\
\text { Lythic Hapludoll }\end{array}$ & $\begin{array}{c}\text { Associação de: Argissolo Vermelho Amarelo } \\
\text { Distrófico com Argissolo Acinzentado Eutrófico e } \\
\text { Neossolo Regossolico Distrófico }\end{array}$ & $2 a b c / 4 p$ \\
\hline SGe - MTo - SNk & $\begin{array}{c}\text { Typic Natraqualf - Vertic Argiudoll - } \\
\text { Typic Natraqualf }\end{array}$ & $\begin{array}{c}\text { Associação de: Planossolo Hidromorfico Salico com } \\
\text { Chernossolo Argilúvico Ortico vértico e Planossolo } \\
\text { Natrico Carbonático }\end{array}$ & $2(a b) c / 4 p$ \\
\hline VGk -MTo & Typic Paludert - Typic Argiudoll & $\begin{array}{l}\text { Associação Vertissolo Hidromorfico Carbonático e } \\
\text { Chernossolo Argilúvico Ortico vértico }\end{array}$ & $2 a b c$ \\
\hline MEo-VGk & Typic Argiudoll - Typic Paludert & $\begin{array}{c}\text { Associação Chernossolo Ebanico Ortico vértico com } \\
\text { Vertissolo Hidromorfico Carbonatico }\end{array}$ & $2 \mathrm{abc}$ \\
\hline GMd - RU & Typic Haplaquoll - Udifluvent & $\begin{array}{l}\text { Associação Gleissolo Melânico Distrófico com } \\
\text { Neossolos Flúvicos }\end{array}$ & $4 \mathrm{P}$ \\
\hline O-GMd & Typic Haplaquoll - Histosol & $\begin{array}{c}\text { Associação Organossolo com Gleissolo Melânico } \\
\text { Distrófico }\end{array}$ & $3(\mathrm{a}) / 4 \mathrm{P}$ \\
\hline RLe - AR & Lithic Hapludoll & $\begin{array}{l}\text { Neossolo Litólico Eutrófico com afloramentos } \\
\text { rochosos }\end{array}$ & $3(\mathrm{a}) / 6$ \\
\hline
\end{tabular}

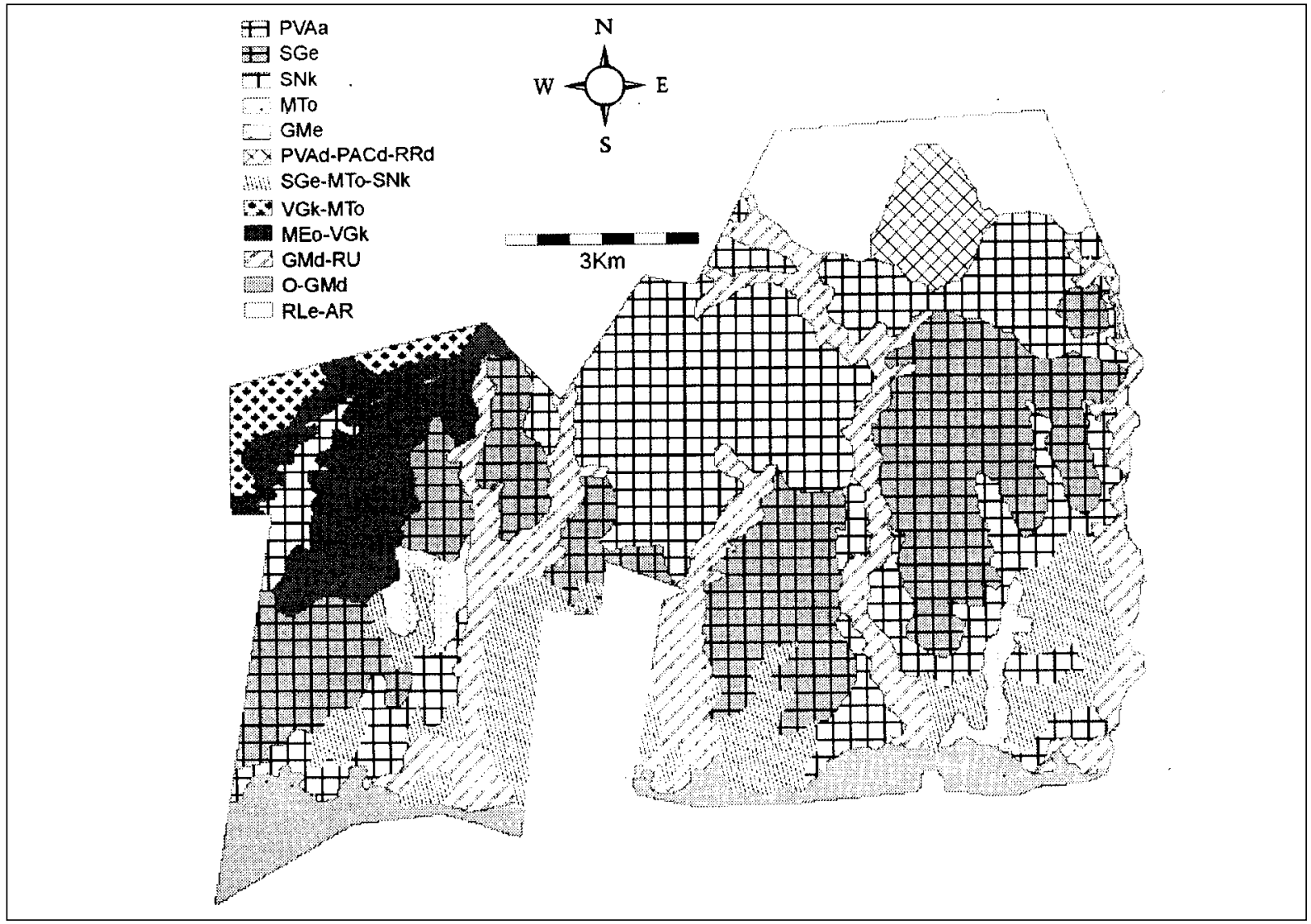

Figura 2 - Mapa de Solos da Fazenda Pantanoso

Ciência Rural, v.34, n.6, nov-dez, 2004. 


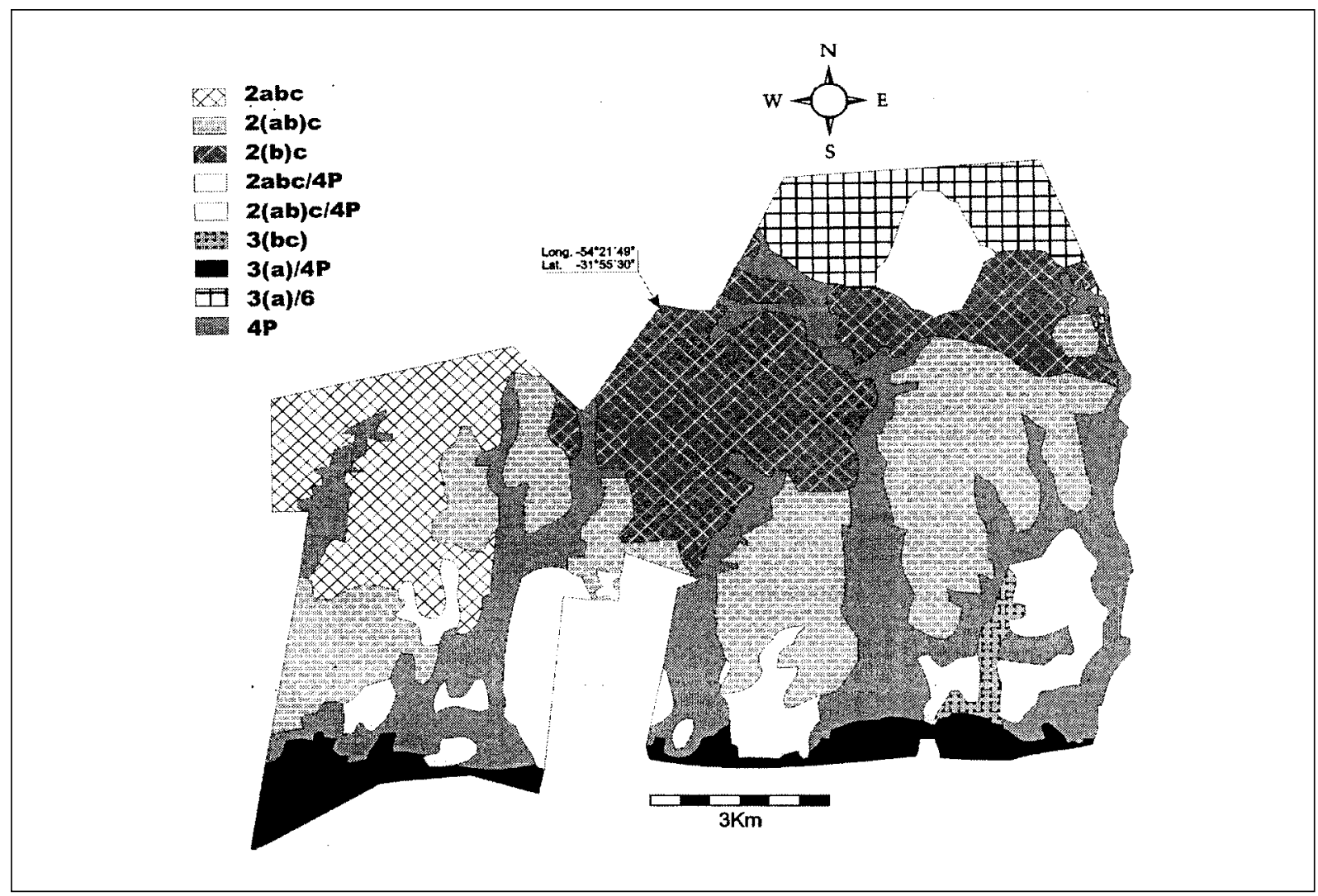

Figura 3 - Mapa das classes de aptidão de uso agrícola dos solos da Fazenda Pantanoso

estudo. Os Planossolos Hidromórficos Eutróficos (SGe) com subgrupo de aptidão 2(ab)c (2722ha), ou seja, com aptidão restrita para agricultura nos sistemas de manejo primitivo (A) e intermediário (B) porém regular no avançado (C) constituem uma importante área de cultivo de arroz irrigado, que, quando drenados, podem ser também usados com pastagem e cultivos como milho e sorgo. Os Planossolos Solódicos (SNk), Organossolos (O) e áreas de Gleissolos Melânicos Distróficos (GMd) muito mal drenados ou sujeitos a inundação enquadram-se na classe 4p (2753ha), ou seja, são regulares para pastagem plantada ou natural melhorada e/ou reflorestamento, com espécies adaptadas a cada tipo de solo. Os Neossolos Litólicos (RLe), que se enquadram na classe 3(a)/6 (696ha), devem ser usados para preservação permanente (classe 6), apesar de permitirem o uso com agricultura em sistema de manejo primitivo nas áreas de classe 3(a).

$\mathrm{O}$ uso atual da fazenda mostra que os Argissolos, Chernossolos e Vertissolos são usados para pastagem, sendo o solo coberto com campo com gramíneas e outras espécies de baixo porte. Uma área extensa com Planossolos e Gleissolos é usada para cultivo de arroz irrigado em rodízio com pastagem plantada ou melhorada; e outra em que culturas anuais como milho, semente de forrageiras são alternadas com pastagem cultivada. Matas ciliares (em Planossolos, Gleissolos e Organossolos) e bosques de altitude (em Neossolos) constituem a mata nativa da área e pequenos bosques de eucaliptos também ocorrem na fazenda. Corpos d'água (açudes) e banhados complementam o uso da fazenda.

\section{Zoneamento ambiental}

O mapa de zoneamento ambiental foi produzido pela integração das informações da aptidão de uso agrícola com a introdução da legislação ambiental vigente, que define as áreas de: preservação permanente, áreas de conservação, de uso intensivo e de diferentes restrições de uso de acordo com a legislação vigente na época (Lei Estadual № 9519/ 92, de 21/01/92: Código Florestal do Rio Grande do Sul e a Lei Federal № 6.938/81, de 31/08/81: que estabelece a Política Nacional do Meio Ambiente) e, quando necessário, sendo mais restrito no uso do que determina a lei ambiental no estado do Rio Grande do 
Sul. Comparando este mapa com o da aptidão de uso dos solos, verifica-se o surgimento das classes de preservação da mata nativa, das áreas com declividades superiores a $25 \%$, definidas como áreas de conservação e os banhados e áreas de inundação ao longo dos sistemas de drenagem, definidas como áreas de preservação permanente, pela legislação ambiental. As áreas usadas com cultivos anuais e pastagem ou somente pastagem se sobrepõe nos mapas.

Conflitos de uso

Pela sobreposição e cruzamento do PI6 uso atual, com o PI7 zoneamento ambiental, classificando as áreas segundo: a) sub-utilizadas, áreas utilizadas com intensidade menor que a sugerida como limite indicado no zoneamento, b) adequado, áreas de uso condizente com a aptidão, c) sobre-uso, áreas utilizadas mais intensamente que o indicado e áreas de recuperação e d) áreas de conflito ambiental, cujo uso fere as Leis Ambientais citadas acima, originouse o mapa de conflitos de uso (Figura 4).

Considerando-se que a pecuária desenvolvida sobre pastagem em campo melhorado e bem manejado, tradicional na região, pode ser considerado uso adequado para os solos e ambientes em que são encontrados, os conflitos de uso dos solos da Fazenda Pantanoso restringem-se às classes 3(a)/ 6 e 4P usadas com lavoura e pastagem, indicando sobre-uso; ou áreas das classes 2abc, 2(b)c, 2(ab)c, aptas para culturas anuais e sendo usadas com campo ou reflorestamento com eucalipto, constituindo subuso; e áreas de preservação permanente, usadas com arroz-pastagem, ou reflorestamento com eucalipto, caracterizando conflito ambiental, constituem os conflitos de de uso da Fazenda Pantanoso.

\section{CONCLUSÕES}

As classes de solos que predominam na fazenda Pantanoso são os Planossolos, Argissolos, Chernossolos, Vertissolos, Gleissolos, Organossolos e Neossolos, que foram mapeados como unidades simples ou associações, confirmando as informações contidas nos mapas de solos existentes no Uruguai. Os delineamentos que definem a distribuição geográfica das unidades de mapeamento foram revisados, e em algumas áreas foram alterados. Os solos desta fazenda apresentam ampla faixa de aptidão de uso, facilitando o trabalho de zoneamento ambiental e ecológico da mesma e a implementação deste uso indicado, originará variadas alternativas se uso para a fazenda.

Considerando que a tradicional pecuária de corte desenvolvida sobre campo nativo melhorado, pode ser considerada adequada para este ambiente, os conflitos de uso dos solos, restringemse a uma área reduzida da fazenda, encontrada ao longo de sistemas de drenagem, ocupada com lavouras de arroz, área esta que, por lei, constitui

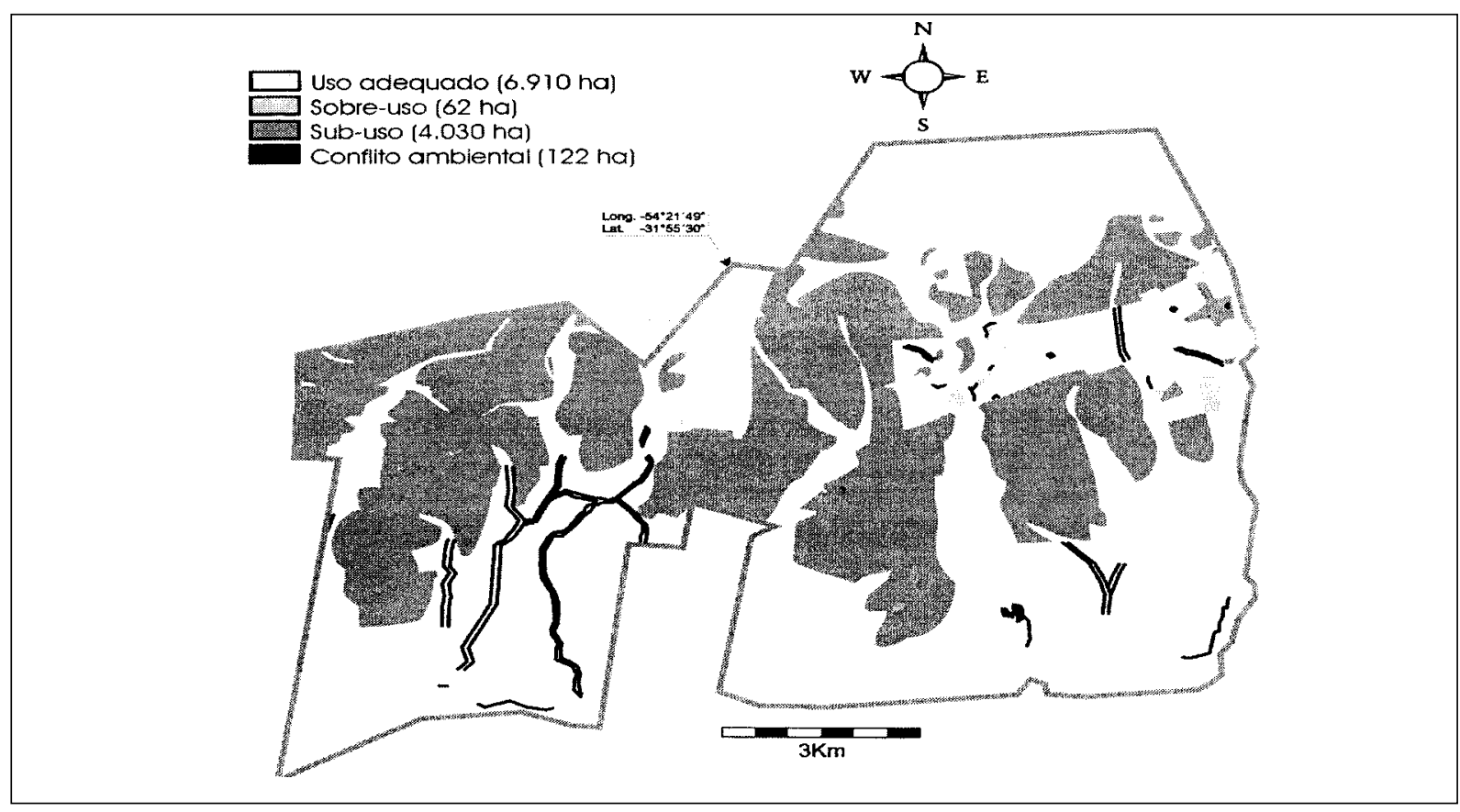

Figura 4 - Mapa de conflitos de uso da Fazenda Pantanoso.

Ciência Rural, v.34, n.6, nov-dez, 2004. 
área de preservação ambiental e, por conseguinte, seu uso constitui conflito relacionado ao zoneamento ambiental.

As ferramentas de geoprocessamento e sensoriamento remoto utilizadas, permitiram atingir os objetivos do presente estudo, ou seja, auxiliar na gestão agroecológica da Fazenda Pantanoso, visto que pela sobreposição de planos de informação foi possível definir e delinear áreas indicadas aos diferentes usos, para subsidiar o planejamento de uso da fazenda.

\section{REFERÊNCIAS BIBLIOGRAFICAS}

ALTAMIRANO, A. et al. Carta de reconecimiento de suelos del Uruguay - Tomo I. Classificacion de Suelos. Montivideu, Uruguai : Ministerio de Agricultura y Pesca, 1976. p.96.

BURROUGH, P.A. Principles of geographical information systems for resources assesment. London : Claredon, 1987. p.193.

CROSTA, A.P. Sensoriamento remoto. Anuário Fator Gis 97: o guia de referência de geoprocessamento. Curitiba : SAGRES, 1997. p.188.

DURÁN, A. et al. Carta de reconecimiento de suelos del Uruguay - Tomo III Descripcion de las Unidades de Suelos. Montevideo, Uruguay : Ministerio de Agricultura y Pesca, 1979. p.452.

DURÁN, A. Los Suelos del Uruguay. Montevideo, Uruguay : Editorial Agropecuaria Hemisferio, 1985. p.397.

EMBRAPA, Centro Nacional Pesquisa de Solos. Sistema Brasileiro Classificação de Solos. Rio de Janeiro : EMBRAPA Solos, 1999. p.412.

FARSHAD, A.E; ZINCK, J.A. Seeking agricultural sustainability. Agriculture, ecosystems and environment, Amsterdam, 1993. V.47, p.1-12.

LEPSCH, I.F. Manual para levantamento utilitário do meio físico e classificação de terras no sistema de capacidade de uso. 4. Apr do manual brasileiro para levantamento da capacidade de uso da terra. Campinas: Sociedade Brasileira de Ciência do Solo, 1983. p.175.

MIRANDA, E.E. et al. Sistemas de informações geográficas para avaliação do impacto ambiental e da sustentabilidade agrícola. In : ENCONTRO DA SOCIEDADE BRASILEIRA DE SISTEMAS DE PRODUÇÃO, 2., 1995, Londrina. Anais... Londrina, 1995. p.301.

PIROLI, E.L. et al. Análise do uso da terra na microbacia do Arroio do Meio - RS, por sistema de informações geográficas e imagem de satélite. Ciência Rural, v.32, n.3, p.407-413, 2002.

RAMALHO FILHO, A.; BEEK, K.J. Sistema de avaliação da aptidão agrícola das terras. 3.ed. Rio de Janeiro ; EMBRAPA - CNPS, 1995. p.65.

RIO GRANDE DO SUL. Atlas Agroclimático do Estado do Rio Grande do Sul. Porto Alegre, 1989. 3v.

RIO GRANDE DO SUL. Macrozoneamento agroecológico e econômico do Estado do Rio Grande do Sul. Porto Alegre : Secretaria da Agricultura e Abastecimento, 1994. V.1, 307p.

SANTOS, U.P. dos et al. Diagnóstico ambiental da bacia hidrográfica da Baía de Sepetiba. Rio de Janeiro : Universidade Federal do Rio de Janeiro - UFRJ, Empresa Brasileira de Pesquisas Agropecuárias - EMBRAPA, 1996. CD-ROOM.

SANTOS, F.J. Gestão agroecológica de microbacias através de técnicas de geoprocessamento e sensoriamento remoto: caso Pantanoso. 1999. 86f. Dissertação (Mestrado) - Centro Estadual de Pesquisa em Sensoriamento Remoto e Meteorologia. CEPSRM/UFRGS.

STALLINGS, J.H. Soil conservation. New Jersey : Prentice Hall, p.575.1967.

STRECK, E.V. et al. Solos do Rio Grande do Sul. Porto Alegre: EMATER/RS; UFRGS, 2002. p.107.

USA, United States Department of Agriculture. Keys to soil taxonomy. 6.ed. Washington, 1994. p.545.

ZINCK, J.A; FARSHAD, I. Issues of sustainability and sustainable land management. Can J Soil Sci, v.75, p.407-412, 1995. 